\title{
Measuring the Success of Information Systems (IS) from Users' Point of View Using Goodhue Index
}

\author{
Parviz Saeidi (Corresponding author) \\ Department of Management and Accounting, Aliabad katoul Branch \\ PO Box: 49417-93451, Islamic Azad University, Aliabad katoul, Iran \\ Tel: 98-371-0735Ｅ-mail: Dr.parvizsaeedi@yahoo.com
}

Azin Malek Marzban

Department of Public Administration, Aliabad katoul Branch

Islamic Azad University, Aliabad katoul, Iran

Received: Nov. 4, 2012 Accepted: December 27, 2012 Published: June 1, 2013

doi:10.5296/ajfa.v5i1.2629 URL: http://dx.doi.org/10.5296/ajfa.v5i1.2629

\begin{abstract}
Nowadays Information systems play a decisive role in success or failure of an organization. Design and deployment of information systems and costly technology investments aim at improving organizational and individual performance. The success of such investments should be evaluated. For effective function of the organization, information systems should be applicable and acceptable by employees. Users' assessment model about Task / System fit has been suggested by Goodhue as an indicator to measure the success of information systems in the field of quantitative information in managerial decisions. The purpose of studying Task/System fit (TSF), individual abilities and system characteristics and policies is evaluating achievement of the system. This research assessed the users' evaluation and checking information system achievements in Khatamol-Anbia hospital in Gonbad in Golestan province, Iran during 1389.The method of data collecting was Goodhue questionnaire with changes in environmental conditions. The aim of this field- study research was application and the executive method was descriptive - correlation. The statistical tests were performed using regression and Eviews6 and Excel software. Results showed that information systems in Khatamol-Anbia hospital were successful according to Goodhue index and Research hypotheses were confirmed.
\end{abstract}

Keywords: Information, System, Information system, Work/system proportion 


\section{Introduction}

According to the increasing role of information in organizations and their needs to have these kinds of information in order to continue their activities, the importance of information system (IS) is manifested. Evaluating the role of this information in organizations and achieving a useful information system that can lead to organizations' progress and development is of importance.

Hospital management information system has been activated over night and day in massive network of workstations and covers all related operational process since the patient's admission till discharge. This automated system is capable of responding to all needs and requests of medical and clinical affairs as well as performing all administrative-financial and scientific- research activities.(Arash,1388,p233).in this research the prosperity of Khatamol-Anbia's information system has been evaluated from users 'point of view.

From a technical perspective, information system is a continuous system that deals with collecting, processing, storing and distributing information to assist organization's decision making and control. Any activity which is done by the computer is called system or information system. Each information system is composed of five elements that include people, procedures, data, software, hardware. Procedures dictate to people how to transform data into information (Jordan \& Machesky, 1990, p3). Information systems are means for receiving, transmitting, retrieving, storing, processing and display of information. Many empirical studies on management information systems literature (MIS) want users as a success index to assess the mentioned system. Member assessments are discussed under various titles, such as points of view, information satisfaction, valuing the management information systems, data networking trends, value and utility for users, etc( Goodhue,1992,p311).

The main objectives of information systems (IS) are policies, organizational structures, spending programs and creating value by improving performance (Crowston \& Treacy, 1986).

Many researchers have expressed the relationship between features / policiles, evaluation, user operation and performance in a linear design which is shown in figure 1 (Davis, 1989, \& Doll \& Torkzadeh, 1991).

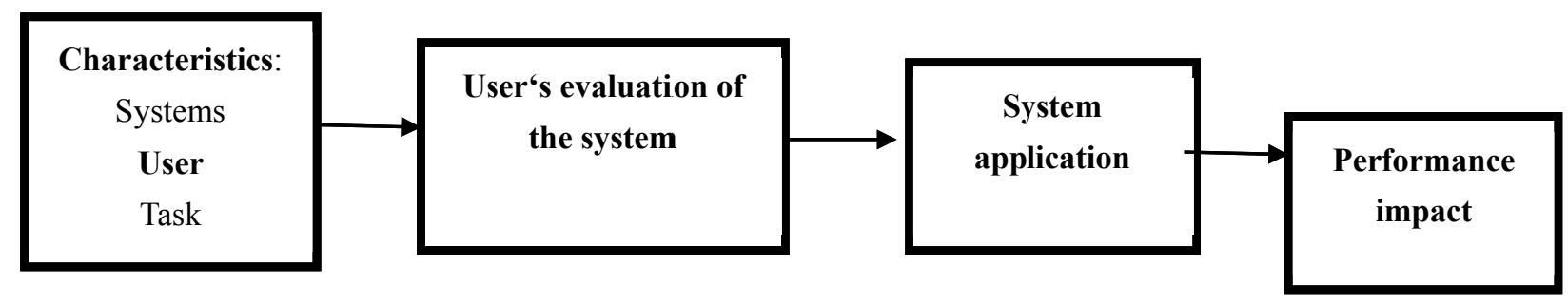

Figure 1. shown an example of a link between systems and performance

Task/System fit is an extent to which an information system or system environment help people accomplish their tasks Or is the proportion that exists within the work requisites and the 
role of (MIS) environment (Goodhue, 1988).

Goodhue believes that most of user assessments have made the distinction between job requirements and individual needs unclear. That results in more uncertainty with performances. He believed that the success of the system according to user evaluation based on Task/System fit would make a closer relationship with task performance and the researchers' criteria for evaluation the system by the user should focus on the Task/Systemfit.

Criteria used in 35 studies focused on the five following structure (Goodhue, 1992, p308). 1-Features / System Policies 2-Task/System fit 3-Expected consequences of use 4-Impact on systems 5-Performance effects

\section{Literature Review}

Fichbein \& Ajzen in 1975 Conducted research on the theory of rational performance. They believed that how to deal with technology is a kind of behavior. Person behavior is formed on the basis of his attitude and also suggests that person behavior depends on his attitude as well as his subjective norm.

Baily \& Pearson in 1983 conducted a study under the user's overall satisfaction. They came to this result that user job satisfaction is an important factor which is in relation with the use of information.

Rogers in 1995 directed a research on acceptance and innovation of information technology. In his research he found five innovative characteristics that influence the selection process. These five features were: Comparative advantage, Complexity, observable, Possibility of testing and Compatibility.

Daivis in 1989 done a research on user acceptance of information technology. He declared that two factors play a key role in the acceptance of information technology. First is individual's perception of usefulness of the technology and the second one is facility in using the technology.

Goodhue in 1992 studied user evaluation of information systems. Classification criteria used in thirty-five research in the field of information systems management were reviewed by him. All these studies emphasized on sufficient information, understanding of information systems, usefulness the systems, and opinions of the users. Many of them are objective and real, like system features, while many of them exist in users' minds.

Goodhue \& Thompson in 1995 and 1998 conducted Studies as Appropriateness of technology and tasks. Facilities in using software and hardware, Compatibility, Accessibility, Accuracy and timeliness have impact on the appropriateness of technology and tasks.

\section{Materials and Methods}

Aim of this research is application and it is a correlated survey. The study population consisted of all employees, department officials and hospital administrators whose jobs were somehow associated with information systems in Khatamol-Anbia Social security hospital and able to cooperate in collecting data related to hospital information systems. Number of persons, 


\section{Macrothink Institute ${ }^{T M}$}

according to the preliminary investigation is one hundred. Data collection tool is a questionnaire. Needed information collected by this questionnaire and then statistical analysis was done. Given that this research study is based on Goodhue index, the questionnaire asked respondents information on their education, occupation, age, sex, years of service. In order to answer the main questions of the questionnaire Likert continuum is used. Goodhue index was used in this study to measure the success of information systems, So Goodhue questionnaire was used. Experts and users of the systems, including a computer supervisor and an expert of system stats were used. To determine the coefficient of reliability and validity of questions in questionnaire, Cronbach's alpha coefficient was calculated. The overall Cronbach's alpha coefficient for the questionnaires was 0.78 . Cronbach's alpha coefficients for subscales such as Task/System fit, individual abilities and Features of the system policy were $0.76,0.73$ and 0.84 respectively.

\section{Conceptual Model}

One of the assessment methods to assess Task/System fit is users' evaluation model. This model was presented by Goodhue (Goodhue1992). He was an American scientist that suggested this model as a criterion for measuring the success of information systems in the field of quantitative information in managerial decision.

Task/System point of view was provided by Goodhue $(1992,1998)$ and Goodhue - Thompson (1995), as a conceptual basis which aims at evaluating user in order to measure information systems in the field of using recorded information for managers and decision making. His objective was to measure users' opinions and comments. He wanted to know how management information systems (MIS) meet users' business needs. He believed that the Task/system fit can have a close relationship with job performance. He presented his model as follows:

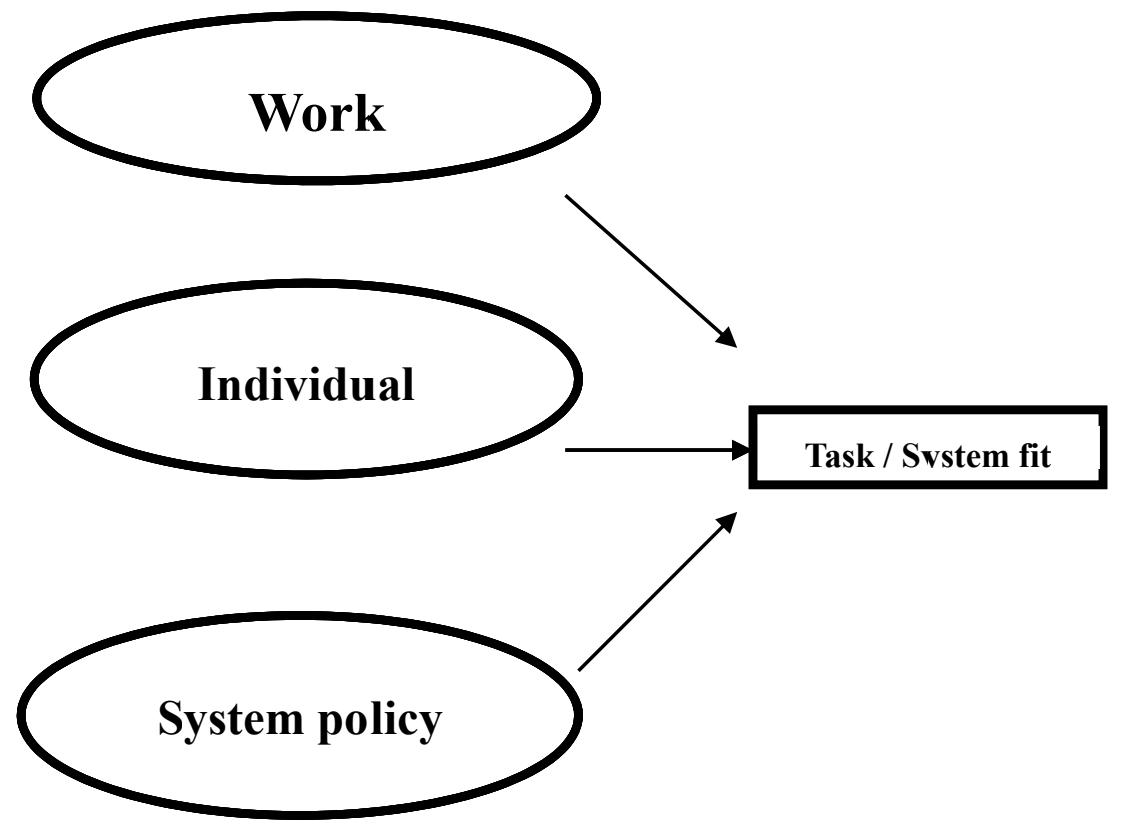

Figure 2. presented his model 
In this model Task / System fit (TSF) can be sought in the characteristics of the system and task that would be adjusted with individual's abilities. In fact, with this model, multidimensional evaluation of the system or system environment can be possible.

\subsection{Methods of analysis}

In order to analyze data, inferential test like correlation was used. T-test for partial regression coefficients and $\mathrm{F}$-statistic for significant regression was used. According to the assumptions of classical linear regression model, Ordinary least squares (OLS) regression method has the estimated optimal conditions. In this method by minimizing the square error, the alpha and beta were estimated. The first step in examining the issue, variables in information systems questions were entered into regression based on Task/System fit, individual abilities and Features of the system policy. After viewing the results, regression improvement was done step by step and an appropriate model was created.

\section{Results}

\subsection{Test the first hypothesis}

$\mathbf{H}_{\mathbf{0}}$ : hospital information systems (IS) based on Task/System fit are successful.

$\mathbf{H}_{1}$ : hospital information systems (IS) based on Task/System fit are not successful.

Table 1. Results of Task/System fit

Dependent Variable: (SER01+SER02+SER03)

\begin{tabular}{|c|c|c|c|c|}
\hline \multicolumn{5}{|c|}{ Method: Least Square } \\
\hline \multicolumn{5}{|c|}{ Included observation: 88} \\
\hline Variable & Coefficient & Std.Error & t-Statistic & Prob. \\
\hline $\mathrm{C}$ & 2.011524 & 0.413231 & 4.867792 & 0.0000 \\
\hline SER04 & 0.197445 & 0.082345 & 2.397787 & 0.0188 \\
\hline SER05 & -0.109154 & 0.059647 & -1.829994 & 0.0709 \\
\hline SER07 & 0.197962 & 0.084966 & 2.329893 & 0.0223 \\
\hline SER08 & 0.148029 & 0.071105 & 2.081822 & 0.0405 \\
\hline SER09 & 0.120024 & 0.085755 & 1.399606 & 0.1654 \\
\hline SER10 & 0.157013 & 0.062314 & 2.519721 & 0.0137 \\
\hline R-squared & 0.422923 & Mean dependent var & 3.74 & \\
\hline Adjusted R-square & 0.380177 & S.D.dependent var & 0.643 & \\
\hline F-statistic & 9.893773 & Durbin-Watson stat & & \\
\hline Prob (F-statistic) & 0.000000 & & & \\
\hline \multicolumn{5}{|c|}{ Substituted Coefficients: } \\
\hline \multicolumn{5}{|c|}{$(\mathrm{SER} 01+\mathrm{SER} 02+\mathrm{SER} 03)=2.0115+0.1974 *$ SER04-0.1091*SER05+0.1979*SER07-0.1480*SER08+0.1200*SER09+0.1570 } \\
\hline \multicolumn{5}{|l|}{ *SER10 } \\
\hline
\end{tabular}


According to Table (1) the overall results and the validity of the model are characterized by prob. (F-statistic) and the greater tendency toward zero the more significantly approved the regression.

Because the Prob. (F-statistic) is equal to zero and the Lack of correlation problem was approved through the Watson-Durbin statistic test which was equal to 1.98 , so we can conclude with $99 \%$ confidence level that $\mathrm{H} 0$ is rejected and $\mathrm{H} 1$ is accepted. In other words, the success of hospital information system is approved.

\subsection{Test the second hypothesis}

$\mathbf{H}_{0}$ : hospital information systems (IS) based on individual capabilities are not successful.

$\mathbf{H}_{1}$ : hospital information systems (IS) based on individual capabilities are successful.

Table 2. Results of individual capabilities

Dependent Variable: (SER11+SER12) / 2

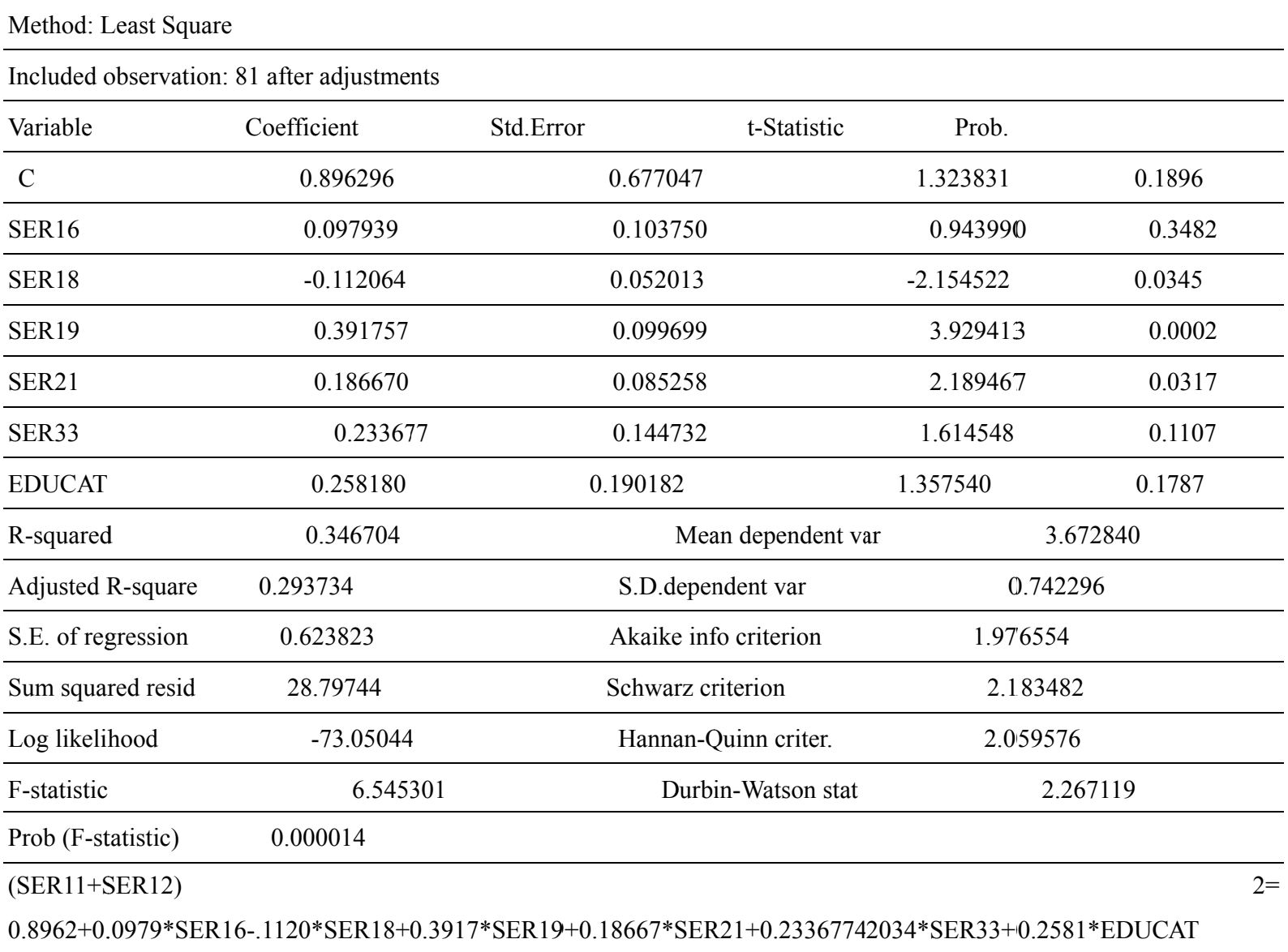

According to the regression test and significant coefficients in table (2), Overall results and the validity of the model is approved by prob. (F-statistic) $=0.00014$, it means that the more closer value to zero, the more reliable the model will be. So we can conclude with $99 \%$ confidence level that $\mathrm{H} 0$ is rejected and $\mathrm{H} 1$ is accepted. Thus success of the hospital 
information systems (IS) hypothesis based on individual ability is approved.

\subsection{Test the third hypothesis}

H0: hospital information systems (IS) based on system characteristics and policy are not successful.

H1: hospital information systems (IS) based on system characteristics and policy are successful.

Table 3. Shows Results of system features

\begin{tabular}{|c|c|c|c|c|}
\hline \multicolumn{5}{|c|}{ Dependent Variable: (SER22+SER23+SER24) / 3} \\
\hline \multicolumn{5}{|l|}{ Method: Least Square } \\
\hline \multicolumn{5}{|c|}{ Date: 09/07/00 Time: 03:14 } \\
\hline \multicolumn{5}{|c|}{ Sample (adjusted): 288} \\
\hline \multicolumn{5}{|c|}{ Included observations: 87 after adjustments } \\
\hline \multicolumn{5}{|c|}{ Convergence achieved after 9 iterations } \\
\hline Variable & Coefficient & Std.Error & t-Statistic & Prob. \\
\hline $\mathrm{C}$ & 0.124913 & 0.483755 & 0.258215 & 0.7969 \\
\hline SER26 & 0.135291 & 0.089745 & 1.507509 & 0.0356 \\
\hline SER28 & 0.315044 & 0.091018 & 3.461336 & 0.0009 \\
\hline SER29 & 0.240088 & 0.105844 & 2.268318 & 0.0260 \\
\hline SER31 & 0.227228 & 0.085010 & 2.672970 & 0.0091 \\
\hline SER32 & 0.095486 & 0.063596 & 1.501452 & 0.0372 \\
\hline $\mathrm{AR}(1)$ & 0.202454 & 0.119195 & 1.698509 & 0.0933 \\
\hline R-squared & 0.533417 & Mean dependent var & \multicolumn{2}{|c|}{3.835249} \\
\hline Adjusted R-square & 0.498423 & S.D.dependent var & \multicolumn{2}{|c|}{0.828862} \\
\hline S.E. of regression & 0.587017 & Akaike info criterion & \multicolumn{2}{|c|}{1.849514} \\
\hline Sum squared resid & 27.56716 & Schwarz criterion & \multicolumn{2}{|c|}{2.047920} \\
\hline Log likelihood & -73.45384 & Hannan-Quinn criter. & \multicolumn{2}{|c|}{1.929406} \\
\hline F-statistic & 15.24319 & Durbin-Watson stat & \multicolumn{2}{|c|}{1.972967} \\
\hline Prob (F-statistic) & 0.000000 & & & \\
\hline Inverted AR Roots & .20 & & & \\
\hline \multicolumn{5}{|c|}{$(\mathrm{SER} 22+\mathrm{SER} 23+\mathrm{SER} 24)=0.1483 * \mathrm{SER} 26+0.3131 * \mathrm{SER} 28+0.2496 * \mathrm{SER} 29+0.2343 * \mathrm{SER} 31+0.0990 * \mathrm{SER} 32+[\mathrm{AR}(1)$} \\
\hline \multicolumn{5}{|l|}{$=0.1960]$} \\
\hline
\end{tabular}

According to the regression test and significant coefficients, Overall results and the validity of the model is approved by prob. (F-statistic) $=0.00$, So we can conclude with $99 \%$ confidence level that $\mathrm{H} 0$ is rejected and $\mathrm{H} 1$ is accepted. In other words, the success of hospital information system is approved.Thus success of the hospital information systems (IS) hypothesis based on 
system characteristics and policy is approved

The success of information systems with the three components; Task/System fit, individual abilities and System characteristics and policy was examined by Goodhue index and all three hypotheses were confirmed.

\section{Conclusion}

The results showed that hospital information systems (IS) based on Task/System fit, are successful. This finding is in one direction with the results of other researchers' such as Goodhue (1988) \& (1995), Billy \& Pearson (1983), Davis and et.al. (1989). Also results showed that hospital information systems (IS) based on individual abilities, have the necessary success. This result is in line with many researchers' findings. Studies done by Fichbein \& Ajzen confirm the above.

Information systems based on system characteristics and policies have the necessary success. This finding is in one direction with the results of other researchers' such as Goodhue (1988), Doll \& Torkzadeh (1988), Goodhue \& Thompson (1995).

Finally, the existing information systems in hospitals from the perspective of users based on Goodhue index have the necessary success. And the findings of this research are in one direction with the results of other researchers' such as Goodhue (1992 and Goodhue \& Thompson (1985).

\section{References}

Arash, Rahman. (1388). Analysis and evaluation of management information systems in hospitals in Iran. First National Conference on Software Engineering, Iran, (223-236)

Bailey, j.E. Pearson. (1983). Development of a tool measuring and analyzing computer user satisfaction. Management Science, 29, 530-584.

Chirs, Ed wards. (1991). The essence of information system, 26-27. London prentice Hall.

Doll, W. j., \& Torkzadeh. (1988). The measurement of end user computing satisfaction. MIS Quarterly, 12(2), 259,276.

Fichbein, M., \& Ajzen, I. (1970). Belief, Attitude, Intentions and Behavior: an introduction to theory and research. Bost on: Addison-Wesley.

Gallivan, M. J. (2001). Organizational adoption, and assimilation of complex technological innovations development and application of a new framework. The data base for advances information systems, 32(3), 51-85.

Goodhue, D. L. (1988). Development and measurement validity of a task technology fit instrument for user evaluations of information systems. Decision science, 29(1), 105-138. http://dx.doi.org/10.2307/249689

Goodhue, D. L. (1992). User evaluations of MIS success: what are really measuring? Proceedings of the Hawaii international conference and information system science, 4, 
303-314.

Goodhue, D. L. (1995). Understanding user evaluations of information systems. Management science, 41(12), 182-184.

Goodhue, D. L., \& Thompson,R. L. (1995). Tark-technology fit and individual performance. MIS Quarterly, 19(2), 213-236.

Rogers, E. M. (1995). Diffusion of innovations. $4^{\text {Th }}$ Edition, the free press, Newyork, NY.

Zaltman, G. Duncan,R., \& Holbeck, J. (1973). Innovations and organizations. Wiley \& sons new york, N.4. 